\title{
Thoughts and Countermeasures on Precision Poverty Alleviation in Higher Vocational Colleges
}

\author{
Songhua Qing \\ Dalian Vocational and Technical College, LiaoNing, Dalian, Code 116035
}

Keywords: Precision Poverty Alleviation, Education Alleviation, Higher Vocational Education

\begin{abstract}
The concept of precise poverty alleviation was a concept put forward by General Secretary Xi Jinping when he investigated the poverty-stricken areas in Western Hunan in 2013. Precise poverty alleviation can effectively help the people in poverty-stricken areas improve their economic income, solve the huge gap between the rich and the poor at the present stage in our country, playing an active role in building a harmonious socialist society and promoting the stable and harmonious development of social order. This paper made a deep analyses including the family characteristics, reasons caused poverty and the value of precise poverty alleviation of poor students in Higher Vocational colleges, and put forward some countermeasures and suggestions, hoping to provide reference for the relevant people.
\end{abstract}

\section{The Value of Precision Poverty Alleviation in Higher Vocational Colleges}

"Balanced development of social economy" was one of the requirements of building a harmonious socialist society. In order to achieve the above goals, our government departments in recent years had continuously increased the support of poor areas, giving a greater tilt in policies, funds and other aspects. From the overall point of view, many efforts of government departments have achieved good results, but from the essence point of view, the poverty problem in poor areas could not be fundamentally solved. Some scholars believed that poverty had two aspects. Therefore, the poverty of people in poor areas was not only economic poverty, but also spiritual poverty. Mental poverty might shackle people's thinking, restrict people's behavior, and further exacerbate people's poverty at the economic level. Therefore, spiritual poverty was the "culprit" of individual poverty. Accurate poverty alleviation in higher vocational colleges can not only teach the people in poverty-stricken areas the skills and skills to support their livelihoods, but also enrich their knowledge, improve their quality and change their spiritual poverty impasse. Based on the above, the value of precise poverty alleviation in higher vocational colleges is enormous. Specifically, it should include the following three points: First, it can highlight the characteristics of Higher Vocational education. Secondly, it can fundamentally solve the problem of poverty in poor areas. The causes of poverty in poor areas were lack of knowledge and skills, lack of competitiveness in the social and economic market, and difficulty in finding jobs with relatively good incomes. Thirdly, it can provide practical basis for poverty alleviation.

\section{The Connotation of Precision Poverty Alleviation in Higher Vocational Colleges}

On November 3, 2013, General Secretary Xi Jinping made it clear in his investigation and poverty alleviation work in Western Hunan that poverty alleviation work "should be planned scientifically, tailored to local conditions, seize key points, continuously improve accuracy, effectiveness and sustainability", "poverty alleviation should be precise, and slogans should not be shouted." This was the first time that the term "precise poverty alleviation" was mentioned. In June 2015, General Secretary Xi Jinping comprehensively expounded the concept of "precise poverty alleviation" in Guizhou on strengthening the work of poverty alleviation and development, and put forward "six precisions", namely "precise target of poverty alleviation, precise project arrangement, precise use of funds, precise measures to households, precise dispatch of people for villages, precise effect of poverty alleviation". The most important thing for precise poverty alleviation is precise identification. The so-called precise poverty alleviation, in the words of ordinary people, is to 
"prescribe the right medicine to cure the disease". Du Yubo, Deputy Minister of education, put forward the general idea of student aid work, which is "to establish a precise funding mechanism as the grasp". The great significance of precise financial aid in Colleges and universities lies in contributing to the poverty alleviation work of the whole society. In short, "Precise Poverty Alleviation" has given new guidance and ideas to college students'financial aid work, and precise financial aid is its inevitable choice.

\section{Analysis on the Current Situation and Problems of Poverty Alleviation in Higher Vocational Education in Liaoning Province}

In Liaoning Province's Education Poverty Alleviation Program (2017-2020), classified measures were clearly put forward to make efforts accurately, to accurately grasp the educational needs of different regions and groups, to find out the implementation path of education poverty alleviation, and to promote the precise implementation of education poverty alleviation policy and the precise distribution of poverty alleviation funds. Focusing on improving the basic cultural quality and technical skills of the poor, we should vigorously develop vocational education and training, and focus on running a number of specialties with social needs, quality of running schools and guaranteed employment, so as to comprehensively enhance the ability of people in poor areas to obtain employment and get rid of poverty and become rich. Through investigation and analysis, the current situation of precise poverty alleviation in Higher Vocational Education in our province has been analyzed, which shows the following situations:

(1) Governments at all levels attach great importance to supporting policies that need to be upgraded

The Liaoning Provincial Committee and the provincial government attach great importance to the education of students with financial difficulties. The provincial education department and other departments have successively promulgated policies and measures to support students. The financial aid system for poor students in Liaoning Province covers the period from pre-school to postgraduate education, and strives to ensure that every student with financial difficulties can enter school smoothly.

(2) Deepening organizational construction with limited resources for team building

Most higher vocational colleges have established a complete organizational structure. The Student Aid Management Center is set up in the Student Work Department. Special teachers were responsible for the aid work. The Counselors in the School Work Office were responsible for the aid work, and the corresponding office facilities were provided. From the establishment of school-funded organizations, the allocation of full-time staff of colleges and departments to the improvement of office equipment, we can achieve the unified management and coordination of the funded work, ensure the implementation of the funding policy, enhance the timeliness and refinement of the funded work, realize the organic combination of the funded work and the educating work, and ensure the healthy and sustainable development of the funded work.

(3) Paying attention to poverty and paying more attention to financial aid than educating people

At present, the government, universities and all walks of life attached great importance to the financial aid work for students with financial difficulties at home. The commitment of the provincial government of Liaoning Provincial Committee of the CPC to "never let a student drop out of school because of financial difficulties at home" has been basically realized, and great achievements were made in the financial aid work. Nevertheless, there was no need to avoid that although the main purpose of financial aid work has been to solve the worries of students with financial difficulties in their families, resulting in the lack of responsibility and gratitude consciousness of the students. It was worth pondering over the phenomenon of emphasizing subsidies over educating people and emphasizing material over spiritual. The function of subsidizing and educating people was not well developed. The subsidizing work has become a "poverty alleviation" project, which caused tension and contradiction among the students. Some of the assisted students had serious thought of "waiting, depending and wanting", lacking self-reliance, self-improvement and positive enterprising spirit. The humanistic care and educational appeal of the 
subsidy work itself have been weakened and "spiritual poverty alleviation" can not be achieved.

\section{The Way of Precision Poverty Alleviation in Higher Vocational Colleges}

(1) Further clarify the precise positioning of poverty alleviation in Higher Vocational Colleges

Higher vocational colleges should further clarify their own position and responsibilities in the precise poverty alleviation work, and accurately dock with poor mountainous areas according to their own disciplinary advantages and professional background. On the basis of precise self-analysis of its own scientific research advantages, professional advantages, teachers' advantages and industry advantages, higher vocational colleges combining their own advantages with the needs of poor mountainous areas, increasd skills training and scientific and technological assistance to the population in poor areas, and gave full play to their own advantages in poverty alleviation work.

(2) Enlarging the Reform of Enrollment System

Due to economic conditions and low quality of teaching in poor areas, students' quality and achievement were quite different from those in economically developed areas. If the performance criteria were used as the basis for judging whether students can enter higher vocational colleges or not, many students from poor families will be "excluded" from the performance threshold. The above situation was obviously contrary to the idea of precise poverty alleviation in Higher Vocational colleges. Therefore, higher vocational colleges should strengthen the reform of the enrollment system, incline students in poor areas to the enrollment system, and ensure that students with relatively poor performance in poor areas can also get the opportunity to enter higher vocational colleges and improve their quality. Of course, in addition to the above preferential policies, higher vocational colleges can actively carry out special enrollment plans, and use media publicity to promote special enrollment plans, to ensure that students in poor areas can understand the preferential policies of Higher Vocational Colleges and government departments, and can actively participate in Higher Vocational Colleges to receive education and improve their quality.

(3) Further Establishing Community Awareness of Precision Poverty Alleviation in Higher Vocational Colleges

In view of the current situation that the precise poverty alleviation in Higher Vocational Colleges in Liaoning Province has not yet formed a joint force, each higher vocational college should establish the community consciousness of precise poverty alleviation. Colleges and universities should strengthen joint efforts in professional teaching, scientific research, training base, school-enterprise cooperation, human resources and other aspects, and concentrate the advantages of higher vocational colleges to provide services to help the region. Taking professional teaching as an example, in the specific operation process, Higher Vocational Colleges in the province can concentrate the high-quality professional strength in the field of agricultural science and technology in the whole province, establish the agricultural science and technology support team of Higher Vocational Colleges in Liaoning Province, and concentrate on solving the difficult problems in the field of agriculture in the areas of assistance.

\section{Discussion}

The value of precise poverty alleviation in higher vocational colleges was enormous. It can not only provide theoretical and practical basis for the development of poverty alleviation in China, but also help poverty-stricken areas get rid of poverty fundamentally and become rich. It can also highlight the characteristics of Higher Vocational Colleges and improve the value of Higher Vocational colleges. From the perspective of precise poverty alleviation, subsidized education in higher vocational colleges was a systematic project. We should follow the guidance from the government, worked as social supervision and school implementation, enhanced college students' sense of self-reliance and self-improvement, organically integrating subsidy and education work, and promote educational equity and social progress. 


\section{References}

[1] Meng Fanhua, Ren Zhinan. Education is the first step to uproot the poverty-stricken vocational education: Guizhou Practice of Precision Poverty Alleviation in Vocational Education [J]. Vocational and Technical Education, 2016 (12): 18-21.

[2] Wang Xue, Motherland Feng, et al. Value and path of precise poverty alleviation in China's Higher Vocational Colleges [J]. Modernization of education, 2018 (5): 247-251.

[3] Yu Changju, Han Yue. An Analysis of the Poverty Characteristics in Rural Areas of Liaoning Province from the Perspective of Precise Poverty Alleviation [J]. Shang, 2016 (15): 73-74.

[4] Yan Hongxin, Gaowei, Wang Zhengyin, et al. On the "Trinity and Four Stages" Ideological and Political Education Model - Innovation of Ideological and Political Education for College Students'Paramilitary Talents [J]. Journal of Xi'an Political College, 2015, 28 (2): 35-38, 71.

[5] Liu Shenglin, Wang Yulin, Zhuang Tianhui. A review of precise poverty alleviation based on literature research [J]. Jiangxi Agricultural Journal, 2015, v.27 (12): 132-136. 